\title{
Caracterización morfoanatómica de las hojas DE FOLLAJE DE ESPECIES DE BAMBUSA (PoACEAE - BAMBusoideAe - BambuseaE)
}

\author{
MorphoanAtomical CHARACTERIZATION OF FOLIAGE LEAVES OF BAMBUSA \\ (PoAceae - Bambusoideae - Bambuseae)
}

\author{
Florencia Bessega 1 , Nancy M. Apóstolo y Gladys E. Yormann*iD
}

\begin{abstract}
Programa Interdisciplinario de Estudios en Plantas Vasculares. Departamento de Ciencias Básicas. Universidad Nacional de Luján. Av. Constitución y Ruta Nacional $N^{\circ}$ 5. Luján (6700). Buenos Aires. Argentina.
\end{abstract}

*glayormann@hotmail.com.ar

Citar este artículo

BESSEGA, F., N. M. APÓSTOLO \& G. E. YORMANN. 2021. Caracterización morfoanatómica de las hojas de follaje de especies de Bambusa (Poaceae - Bambusoideae Bambuseae). Bol. Soc. Argent. Bot. 56: 445-465.

DOI: https://doi. org/10.31055/1851.2372.v56. n4.34355

Recibido: 8 Ago 2021

Aceptado: 18 Nov 2021

Publicado impreso: 20 Dic 2021

Editora: Ana María Gonzalez iD

ISSN versión impresa 0373-580X ISSN versión on-line 1851-2372

\section{SUMMARY}

Background and aims: In Argentina, the genus Bambusa comprises nine introduced taxa, of which the most cultivated are B. multiplex, B. tuldoides and $B$. vulgaris cv. vittata. Bambusa plants are characterized by non-seasonal blooms, after long and variable vegetative periods. The study of the foliage leaf anatomy of woody bamboos is thus usefulness in the taxonomy of Bambusoideae. In order to characterize each species, the micromorphology, anatomy, and ultrastructure of foliage leaf blades are studied.

M\&M: With the aid of optical, scanning electron and transmission electron microscopy, the anatomy of foliage leaf blades of the three species are analysed. Qualitative and quantitative parameters of transverse and longitudinal sections and dissociated material are documented.

Results: The dimensions of the leaf blade showed significant differences between the three species of Bambusa studied. The micromorphology of the foliage leaf blade surface exhibits differential characters between the abaxial and adaxial epidermis between species, such as the presence or absence of microhairs, macrohairs and prickles; silica cell type; degree of cohesion and number of papillae surrounding the stomatal apparatus. The dimensions and characteristics of the fusoid cells and fibers show differences between the species, as well as the micrometric parameters as seen in cross sections.

Conclusions: The morphoanatomical features allows the characterization of the Bambusa species studied.

\section{KeY Words}

Anatomy, epidermis, leaf, micromorphology, woody bamboos.

\section{RESUMEN}

Introducción y objetivos: En Argentina, el género Bambusa está representado por nueve taxones introducidos, de los cuales los más cultivados son $B$. multiplex, $B$. tuldoides y $B$. vulgaris $\mathrm{cv}$. vittata. Los representantes del género se caracterizan por tener floraciones no estacionales, luego de largos y variables períodos vegetativos. El estudio de la anatomía foliar de bambúes leñosos resulta de utilidad para la diferenciación de especies. Con el fin de caracterizar cada entidad, se estudia la micromorfología, anatomía y ultraestructura de sus hojas de follaje.

M\&M: Mediante microscopía óptica, electrónica de barrido y de transmisión se analizan los caracteres de los tipos celulares y de la estructura interna de las hojas de follaje de las tres especies. Se registran parámetros cualitativos y cuantitativos de cortes transversales y longitudinales y disociados de cada una de las especies.

Resultados: Las dimensiones de la lámina de la hoja mostraron diferencias significativas entre las tres especies de Bambusa estudiadas. La micromorfología de la superficie foliar exhibe caracteres diferenciales entre la epidermis abaxial y adaxial de cada especie y entre especies: presencia o ausencia de micropelos, macropelos y aguijones; tipo de células silíceas; grado de cohesión y número de papilas que rodean a los estomas. Las dimensiones y características de las células fusoides y fibras muestran diferencias entre las especies, al igual que los parámetros micrométricos registrados sobre los cortes transversales de las hojas.

Conclusión: Los caracteres morfo-anatómicos en conjunto con aquellos morfológicos permiten la caracterización de las especies de Bambusa estudiadas.

Palabras Clave

Anatomía, bambúes leñosos, epidermis, hoja, micromorfología. 


\section{INTRODUCCIÓN}

La subfamilia Bambusoideae (Poaceae) comprende 125 géneros con unas 1670 especies distribuidas en regiones tropicales y templadas de todos los continentes, excepto en Europa y Antártida (Kelchner \& Bamboo Phylogeny Group, 2013; Soreng et al., 2015, 2017; Rúgolo, 2016a). La tribu Bambuseae (Bambusoideae) abarca 73 géneros con 966 especies de bambúes leñosos tropicales y subtropicales (Clayton \& Renvoize, 1986; Soderstrom \& Ellis, 1988; Mejía et al., 2009; Kelchner \& Bamboo Phylogeny Group, 2013; Soreng et al., 2015, 2017; Rúgolo, 2016a) hasta la región andino-patagónica (Rúgolo, 2016a). Bambusa, perteneciente a la tribu Bambuseae, comprende 131 especies originarias de Asia tropical y subtropical, ampliamente cultivadas en regiones pantropicales de todo el mundo (Rúgolo, 2016b).

En Argentina, el género Bambusa está representado por nueve taxones introducidos: $B$. multiplex (Lour.) Raeusch. ex Schult. \& Schult. f., B. tuldoides Munro, B. vulgaris var. vulgaris Schrad. ex J. C. Wendl., B. vulgaris cv. vittata (Riviére \& C. Riviére) Mc Clure, B. ventricosa McClure, B. oldhami Munro, B. bambos (L.) Voss, B. blumeana ex Schult. \& Schult. f. y $B$. textilis McClure (Rúgolo de Agrasar \& Puglia, 2004; Kelchner \& Bamboo Phylogeny Group, 2013; Rúgolo, 2016b). Sin embargo, las especies principalmente cultivadas son $B$. multiplex, $B$. tuldoides y $B$. vulgaris cv. vittata (Mejía et al., 2009; Rúgolo, 2016b).

$\mathrm{Al}$ igual que otros géneros de la tribu Bambuseae, los representantes del género Bambusa se caracterizan por tener floraciones no estacionales, luego de largos y variables períodos vegetativos, estimados entre 30 a 120 años. El tamaño, forma y el color del culmo o caña, de las hojas del follaje y de las hojas caulinares varían según la especie y son específicos de cada género $\mathrm{y}$, eventualmente, de cada especie. Por lo tanto, los caracteres morfológicos en conjunto con aquellos anatómicos permiten la identificación taxonómica de las especies de bambúes leñosos de floración esporádica y/o monocárpicos (Judziewicz et al., 1999; Lizarazu, 2013; Rúgolo, 2016b).

La mayoría de los estudios anatómicos de los bambués leñosos están referidos a culmos (Metcalfe, 1960, Liese, 1998; Rúgolo de Agrasar \& Rodríguez,
2002, 2003; Guerreiro, 2013; Lizarazu, 2013; Guerreiro \& Rúgolo de Agrasar, 2014; Guerreiro et al., 2016; Yormann, 2017; Yormann et al., 2020). Sin embargo, los estudios anatómicos y morfológicos de las hojas de follaje (de las ramificaciones) de las diferentes especies de bambúes son menos frecuentes. Existen trabajos que mencionan los caracteres de la superficie foliar, como la presencia de tricomas, papilas, células silíceas y células fusoides, que contribuyen a la diferenciación de las entidades (Ghosh \& Negi, 1959; Tateoka, et al. 1959; Metcalfe, 1960; Grosser \& Liese, 1971; Guerreiro et al., 2016; Leandro et al., 2016, 2017, 2018, 2020; Alegría Olivera et al., 2017). Varios autores informan que las características anatómicas y micromorfológicas de las hojas de follaje son útiles para la definición y delimitación de taxones en la subfamilia Bambudoideae, sus tribus y subtribus (Márquez et al., 2011; Leandro et al., 2016, 2017, 2020; Alegría Olivera et al., 2017).

A pesar que existen descripciones de la anatomía foliar y tipos celulares de numerosas especies de bambúes leñosos (Judziewicz et al., 1999; Londoño, 2002; Vieira et al., 2002; Montiel et al., 2006a, 2006b, 2006c, 2006d; Herrera-Giraldo et al., 2009; Guerreiro et al., 2016), es escasa la bibliografía referente a las especies de Bambusa, siendo la mayoría referente a caracteres anatómicos generales (Judziewicz et al., 1999; March \& Clark, 2011; Guerreiro et al., 2016). Sin embargo, no hay suficientes trabajos que muestren una contribución a perspectivas sistemáticas y filogenéticas entre las especies de Bambusa, mediante caracteres anatómicos y micromorfológicos. Sólo Liana et al. (2017) reportan estudios micromorfológicos de la epidermis (características de células silíceas y células buliformes y tipos de tricomas) que proveen importante información para ser utilizados en estudios taxonómicos del género.

$\mathrm{Al}$ igual que la mayoría de los bambúes leñosos, las especies de Bambusa exhiben largos períodos de floración, por lo cual es importante estudiar caracteres morfoanatómicos que permitan identificar a las especies en estado vegetativo. Bambusa multiplex, B. tuldoides y B. vulgaris cv. vittata son los principales representantes del género cultivados en la Argentina. Debido a que estas tres especies, en general, han sido comparadas mediante caracteres morfológicos, el objetivo de este trabajo es estudiar la lámina de las hojas de follaje mediante su 


\section{F. Bessega et al. - Morfoanatomía de hojas de Bambusa}

micromorfología, anatomía y ultraestructura, con el fin de proveer caracteres útiles para aplicar en futuros estudios sistemáticos y filogenéticos del género y/o tribus de la subfamilia Bambuoideae.

\section{Materiales y Métodos}

\section{Colección del material}

En el Jardín Botánico Lucien Hauman de la Facultad de Agronomía (FAUBA, Buenos Aires, Argentina) fueron colectadas muestras de hojas de follaje adultas de Bambusa multiplex, B. tuldoides y B. vulgaris cv. vittata. Quince hojas con características similares de crecimiento fueron seleccionadas al azar de, al menos, tres ejemplares por especie. Las muestras fueron tomadas a altura de pecho, en el tercer nudo desde el ápice de la ramificación. Las hojas colectadas fueron conservadas en etanol $70^{\circ}$, fijador FAA (ácido acético: formaldehído: etanol 96 : agua destilada, 1:2:10:7) o glutaraldehído $4 \%$ hasta su utilización en metodologías para microscopía óptica, microscopía electrónica de barrido y microscopía electrónica de transmisión, según correspondiera.

Fueron determinados parámetros cuantitativos de las dimensiones de las láminas foliares de las tres especies. Para ello, utilizando regla milimetrada, se realizó la medición del largo y ancho de la lámina y ancho de la base y ápice de la lámina.

\section{Material de referencia}

Bambusa multiplex (Lour.) Raeusch. Ex Schult. \& Schult. f.

ARGENTINA. Pcia. Buenos Aires: Villa Ortúzar, cultivada Jardín Botánico, Facultad de Agronomía, UBA, IV-1942 (veg,), Parodi 14408 (BAA). Pcia. Jujuy, Dpto. Ledesma, Sala Calilegua, 2346'S 6446’W. 25-XI-2008 (veg.), Rúgolo et al. 2321 (SI).

Bambusa tuldoides Munro

ARGENTINA. Buenos Aires: Villa Ortúzar, cultivada Jardín Botánico, Facultad de Agronomía, UBA, 31-X-1967 (veg,), J. Cámara Hernández s/n (BAA). Pcia. Jujuy: Dpto. Ledesma, Rio Ledesma, Decoville. 25-XI-2008 (veg.), Rúgolo et al. 2315 (SI) Bambusa vulgaris cv. vittata (Rivière \& C. Rivière) McClure

ARGENTINA. Pcia. Jujuy: Dpto. Ledesma, Sala

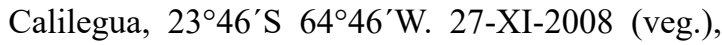
Rúgolo et al. 2325 (SI).

\section{Microscopia óptica (MO)}

Porciones de la parte media de la lámina de todas las hojas de follaje colectadas de las tres especies, fueron tratadas con ácido fluorhídrico al $10 \%$ durante $24 \mathrm{~h}$ para retirar el exceso de sílice. Posteriormente, luego de varios enjuagues con agua destilada, el material fue procesado para su inclusión en parafina, según metodología convencional (D'Ambrogio, 1986; Zarlavsky, 2014). Mediante el uso de micrótomo rotatorio Microm HM 325, se efectuaron cortes transversales y longitudinales ( $20 \mu \mathrm{m}$ de espesor). Los cortes fueron coloreados con safranina-verde rápido y montados en resina sintética, según metodología convencional (D'Ambrogio, 1986; Zarlavsky, 2014).

Para la caracterización de los tipos celulares fueron realizados disociados de las hojas mediante el Método Boodle (D'Ambrogio, 1986; Zarlavsky, 2014). Posteriormente, se efectuó la coloración del material con safranina diluida $1 \%$ y el montaje en gelatina-glicerina.

La descripción de los caracteres cualitativos anatómicos de los cortes y material disociado fue realizada según las consideraciones de Ellis (1976, 1979) y Bamboo Biodiversity Website Iowa State University (2021).

Además, fueron evaluados parámetros cuantitativos (micrométricos) en el corte transversal de la lámina foliar de cada especie como, espesor de hoja (valle y costilla); espesor de epidermis (caras adaxial y abaxial); espesor de cutícula (caras adaxial y abaxial); distancia intervenal; número de "células fusoides"; número de células buliformes; alto y ancho de la célula buliforme principal (Fig. 1). La mención de "valle" y "costilla" se refiere a la zona intercostal y costal, respectivamente, de la lámina foliar en corte transversal. Cuando se hace referencia a "célula fusoide" en este tipo de corte de la lámina foliar, se alude al complejo de células fusoides y espacios intercelulares o cavidades dispuesto perpendicularmente al eje principal de la lámina.

En las preparaciones con material disociado fueron determinados los parámetros cuantitativos de las células fusoides aisladas: largo, ancho y espesor y de las fibras aisladas: largo, ancho de la parte media y del extremo y espesor de pared y (Fig. 1). 

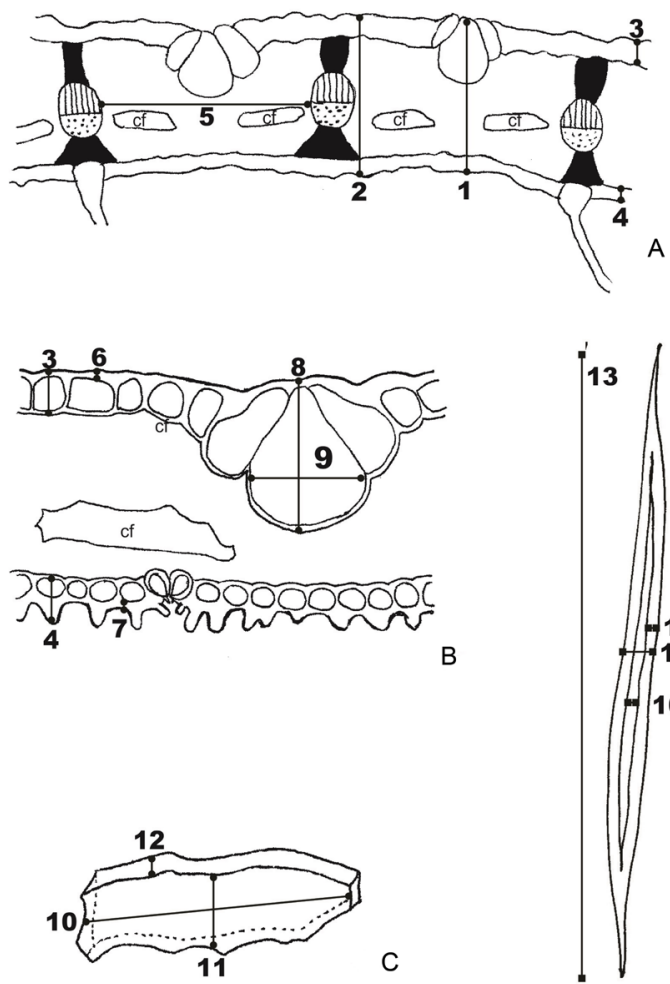

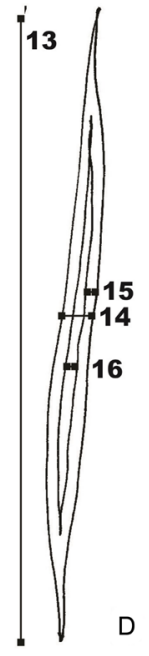

Fig. 1. Parámetros utilizados para la determinación de los datos cuantitativos (micrométricos) de los tipos celulares y la estructura de las hojas de follaje de Bambusa multiplex, $B$. tuldoides y $B$. vulgaris $\mathrm{cv}$. vittata. A, B: Corte transversal. A: Aspecto general. B: Detalle. C, D: Material disociado. C: Célula fusoide. D: Fibra. Parámetros = 1: Espesor de la hoja en el valle (zona intercostal). 2: Espesor de la hoja en la costilla (zona costal). 3: Espesor de la epidermis de la cara adaxial. 4: Espesor de la epidermis de la cara abaxial. 5: Distancia intervenal. 6: Espesor de cutícula de la superficie adaxial. 7: Espesor de cutícula de la superficie abaxial. 8: Alto de la célula buliforme principal. 9: Ancho de la célula buliforme principal. 10: Largo de la célula fusoide. 11: Ancho de la célula fusoide. 12: Espesor de la célula fusoide. 13: Longitud de la fibra. 14: Ancho en la parte media de la fibra. 15: Espesor de la pared en la parte media de la fibra. 16: Diámetro o ancho del lumen en la parte media de la fibra. Abreviaturas = cf: complejo "célula fusoides".

Las preparaciones han sido observadas, medidas y fotografiadas con microscopio óptico Nikon Eclipse 200, con cámara digital Moticam adosada con software para mediciones TSView ${ }^{\circledR}$.
Los datos micrométricos fueron obtenidos en, al menos, 30 campos ópticos al azar por cada parámetro analizado en las preparaciones de los cortes transversales y de los disociados. Los resultados fueron analizados por ANOVA y comparación múltiple de medias (método Tukey), utilizando SPSS 12.0.

\section{Microscopía electrónica de barrido (MEB)}

Para el estudio de la micromorfología de la superficie foliar de cada especie, el material fue acondicionado según la metodología convencional (D'Ambrogio, 1986; Zarlavsky, 2014). Pequeñas porciones de la cara abaxial y de la cara adaxial de la lámina foliar fueron deshidratadas con una batería ascendente de alcoholes, montadas en platinas de aluminio y metalizadas con oropaladio (D'Ambrogio, 1986; Zarlavsky, 2014). La observación y fotografía de los materiales fue realizada con Microscopio Electrónico de Barrido Phillips XL 30 SEM (Servicio de Microscopía Electrónica, Museo de Ciencias Naturales Bernardino Rivadavia, Buenos Aires, Argentina).

Las descripciones micromorfológicas de las hojas fueron efectuadas según Ellis (1979).

\section{Microscopía electrónica de transmisión (MET)}

Pequeñas porciones de las hojas fueron fijadas en glutaraldehido $4 \%$ y buffer fosfato $0.05 \mathrm{M}$, postfijadas en tetróxido de osmio. Posteriormente, fueron deshidratadas en serie gradual de acetona e incluidas en resinas epoxi (Zarlavsky, 2014). Mediante el uso de ultramicrótomo, fueron obtenidos cortes ultrafinos transversales y longitudinales, los cuales fueron montados en grillas de cobre y coloreadas según metodología convencional (Zarlavsky, 2014). Los cortes gruesos fueron coloreados con azul de toluidina y montados en resina sintética para su observación en microscopía óptica.

Las observaciones y micrografías de la ultraestructura de los tipos celulares fueron realizadas mediante MET JEOL JEM 1200EX II (Servicio de Microscopía Electrónica de la Facultad de Ciencias Veterinarias, Universidad Nacional de La Plata).

\section{Resultados}

A pesar que las hojas de las tres especies de Bambusa analizadas muestran características 


\section{F. Bessega et al. - Morfoanatomía de hojas de Bambusa}

anatómicas similares, presentan caracteres estructurales y ultraestructurales y cuantitativos propios de cada una de ellas.

Bambusa multiplex, B. tuldoides y B. vulgaris cv. vittata exhiben hojas de follaje simples ovadolanceoladas, con lámina plana, con margen liso o entero, con base de lámina oval, levemente asimétrica y con ápice agudo. Bambusa multiplex se diferencia significativamente de las dos especies restantes estudiadas porque presenta lámina con menores dimensiones. Bambusa vulgaris $\mathrm{cv}$. vittata es la especie que muestra mayores dimensiones significativas en los parámetros analizados, mientras que $B$. tuldoides presenta valores intermedios, mostrando diferencias significativas (Tabla 1).

\section{Caracteres anatómicos cualitativos}

La descripción anatómica, micromorfológica y ultrestructural de las tres especies en estudio es presentada sobre la base de cada carácter anatómico o tipo celular. De esta manera, principalmente, son expuestas las características generales de la epidermis (Figs. 2-3), los detalles de los estomas (Fig. 2), las particularidades de las células cortas y células buliformes (Fig. 4), los detalles de los macropelos, micropelos y aguijones (Fig. 5), los caracteres generales del mesófilo y la descripción particular del complejo "células fusoides" (Fig. 6) y los aspectos de los haces vasculares y fibras (Fig. 7).

En general, las tres especies tienen la epidermis de la cara adaxial con valles y costillas y una epidermis de la cara abaxial recta (Figs. 2A; 3B, D, F; 4F, G). La cutícula es lisa en ambas epidermis. La epidermis de la superficie adaxial muestra cutícula gruesa, principalmente en la zona de las costillas, mientras que la epidermis de la cara abaxial tiene cutícula delgada (Fig. 2A, B; F, H; Tabla 2).

Las células epidérmicas propiamente dichas son largas, rectangulares, con paredes gruesas y onduladas, con numerosas papilas por célula (Figs. 2C, D; 4A; 5C). En la epidermis de la cara adaxial se observan células epidérmicas no papilosas o con papilas muy cortas, excepto alrededor de los estomas, mientras que la epidermis de la cara abaxial tiene células epidérmicas con abundantes papilas, generalmente elongadas. La distribución de las papilas es uniforme y lineal en la epidermis de la superficie abaxial (Figs. 2A-D, G; 3A-F; 4E, F; 5A; $6 \mathrm{~A}, \mathrm{C})$. Las papilas que rodean a los estomas están presentes en las epidermis de ambas caras de la lámina. En la epidermis de la cara abaxial se pueden observar 4 - 8 papilas, cortas raramente fusionadas, por estoma (2 - 4 papilas a cada lado del estoma), sin conformar cámara supraestromática (Figs. 2D-H; 3A, C, E). En la epidermis de la superficie adaxial, hay 4 a 6 papilas alrededor de cada estoma, algunas de ellas fusionadas o ramificadas, conformando una cámara supraestomática (Figs. 2C; 3B, D, F; 4F). Bambusa multiplex exhibe el mayor grado de fusión de papilas alrededor de los estomas (Figs. 3B; 4F). Las papilas de las células epidérmicas de las tres especies son simples, pudiéndose observar raramente alguna papila ramificada en la epidermis de la cara abaxial de la lámina de $B$. tuldoides.

Se observan células cortas (suberosa y silícea) en ambas superficies foliares, generalmente de a pares (Figs. 4A-C; 5C). En las tres especies en estudio, la epidermis de la cara abaxial exhibe células cortas con contorno cuadrangular con su parte media poco estrecha y, también en forma de silla de montar con la parte media muy angosta (Figs. 2D; 3A, E; 4E). Sin embargo, en la epidermis de la cara adaxial, sólo se encuentran las células silíceas de forma de silla de montar con la parte media muy angosta (Figs. 2C; 3B, D, F; 4D).

Las hojas de Bambusa multiplex, B. tuldoides y $B$. vulgaris $\mathrm{cv}$. vittata son anfiestomáticas. Los estomas

Tabla 1. Parámetros cuantitativos morfológicos promedio de las hojas de follaje de Bambusa multiplex, $B$. tuldoides y $B$. vulgaris $\mathrm{cv}$. vittata. Letras diferentes en cada fila indican diferencias significativas entre especies para $p \leq 0,05$ (Tukey).

\begin{tabular}{|lllllll|}
\hline & B. multiplex & & \multicolumn{2}{c|}{ B. tuldoides } & \multicolumn{3}{c|}{ B. vulgaris cv. vittata } \\
\hline Largo de la lámina $(\mathrm{cm})$ & 4,20 & C & 16,00 & b & 20,40 & a \\
Ancho parte media de la lámina $(\mathrm{cm})$ & 0,90 & C & 2,11 & b & 4,54 & a \\
Ancho del ápice de la lámina $(\mathrm{cm})$ & 0,20 & C & 0,90 & b & 1,60 & a \\
Ancho de la base de la lámina $(\mathrm{cm})$ & 0,50 & c & 1,40 & b & 2,30 & a \\
\hline
\end{tabular}


Bol. Soc. Argent. Bot. 56 (4) 2021
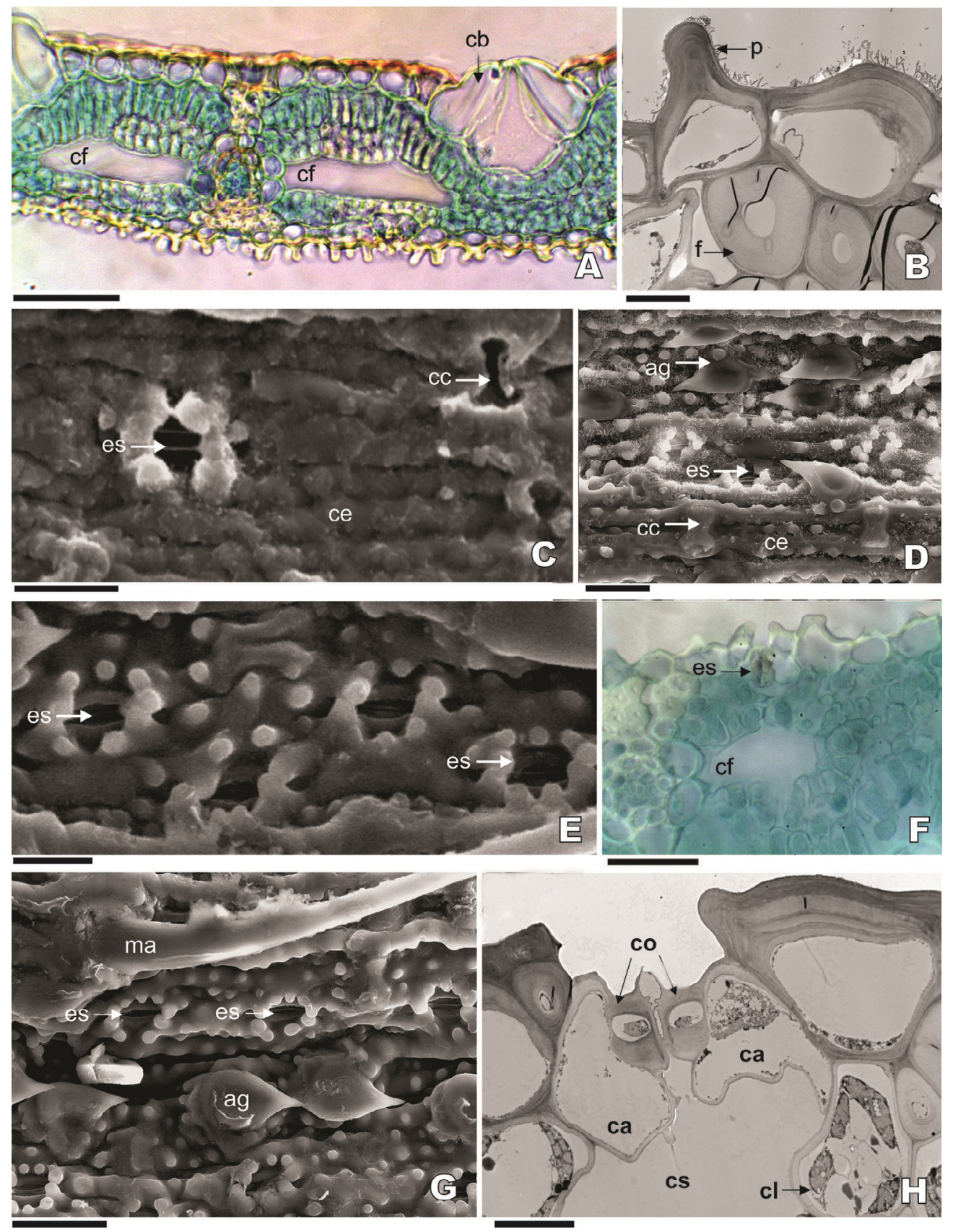

Fig. 2. Epidermis de las hojas de follaje de Bambusa. A-D: B. vulgaris cv. vittata. A: Aspecto general (MO, corte transversal). B: Células epidérmicas de la cara abaxial (MET, corte transversal). C: Superficie adaxial (MEB, micromorfología). D: Superficie abaxial (MEB, micromorfología). E, F: B. multiplex. E: Superficie abaxial (MEB, micromorfología). F: Epidermis de la cara abaxial y mesófilo (MO, corte transversal). G, H: B. tuldoides. G: Superficie abaxial (MEB, micromorfología). H: Estomas y células anexas, epidermis de la cara abaxial (MET, corte transversal). Abreviaturas = ag: aguijón; ca: célula anexa del aparato estomático; cb: célula buliforme; cc: célula corta; ce: célula epidérmica larga; cf: complejo "célula fusoides"; cl: célula de clorénquima; co: células oclusivas del estoma; cs: cámara subestomática; es: estoma; f: fibra; ma: macropelo; p: papila de la célula epidérmica larga. Escalas = A: $50 \mu \mathrm{m} ; \mathrm{B}, \mathrm{H}: 5 \mu \mathrm{m} ; \mathrm{C}-\mathrm{G}: 25 \mu \mathrm{m}$. 

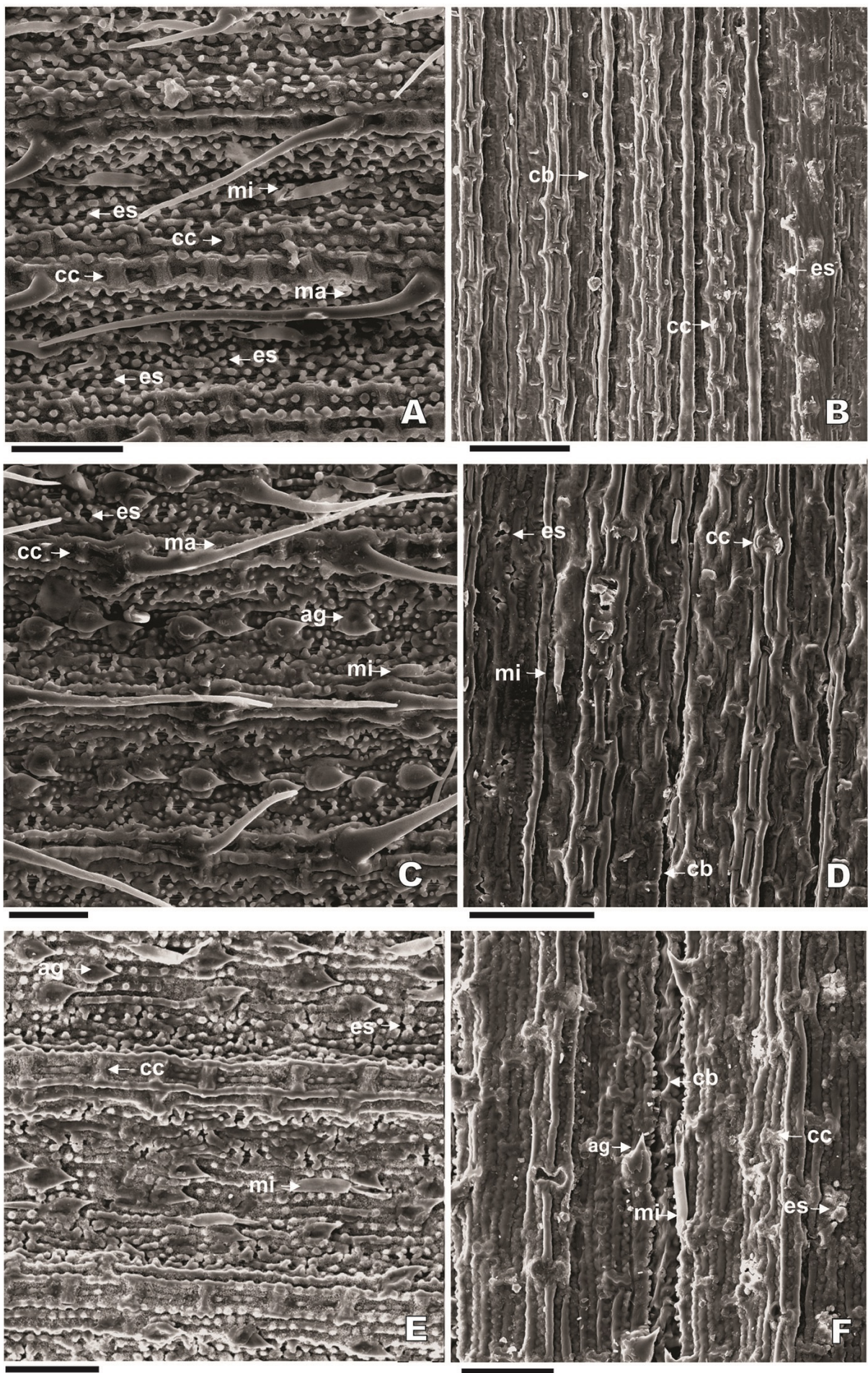

Fig. 3. Micromorfología de las hojas de follaje de Bambusa (MEB). A, B: B. multiplex. C, D: B. tuldoides. E, F: B. vulgaris Cv. vittata. A, C, E: Superficie abaxial. B, D, F: Superficie adaxial. Abreviaturas = ag: aguijón; cb: células buliformes; cc: célula corta; es: estoma; ma: macropelo; mi: micropelo. Escalas = A, C, E, F: 50 $\mu \mathrm{m} ; \mathrm{B}, \mathrm{D}: 100 \mu \mathrm{m}$. 
Bol. Soc. Argent. Bot. 56 (4) 2021
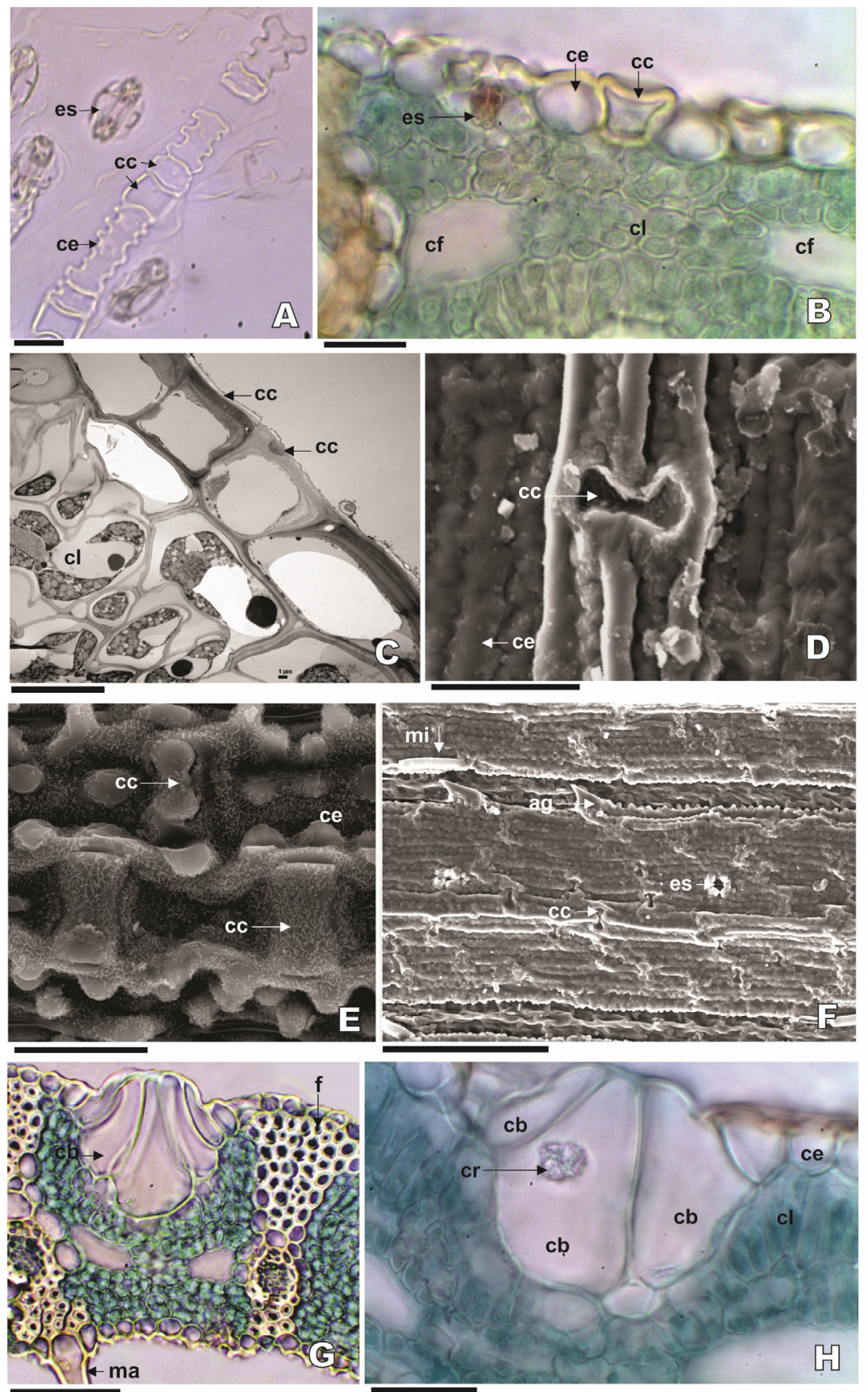

Fig. 4. Epidermis de hoja de follaje de Bambusa. A-F: Células cortas. A-C: B. tuldoides. A: Epidermis de la cara abaxial (MO, material disociado). B: Epidermis de la cara abaxial y mesófilo ( $\mathrm{MO}$, corte transversal). C: Par de células cortas (MET, corte transversal). D: B. vulgaris var. vittata, superficie adaxial (MEB, micromorfología). E: B. multiplex, superficie abaxial (MEB, micromorfología). F-H: Células buliformes. F: $B$. vulgaris var. vittata, superficie adaxial (MEB, micromorfología). G: B. multiplex, aspecto general (MO, corte transversal); $\mathbf{H}: B$. vulgaris var. vittata, detalle de células buliformes ( $\mathrm{MO}$, corte transversal). Abreviaturas = ag: aguijón; cb: célula buliforme; cc: célula corta; ce: célula larga; cl: célula del clorénquima; cr: cristal; es: estoma; f: fibras; ma: macropelo. Escalas = A, B, D-F, I: $20 \mu \mathrm{m}$; C: $10 \mu \mathrm{m}$; G: $100 \mu \mathrm{m} ; \mathrm{H}: 50 \mu \mathrm{m}$. 

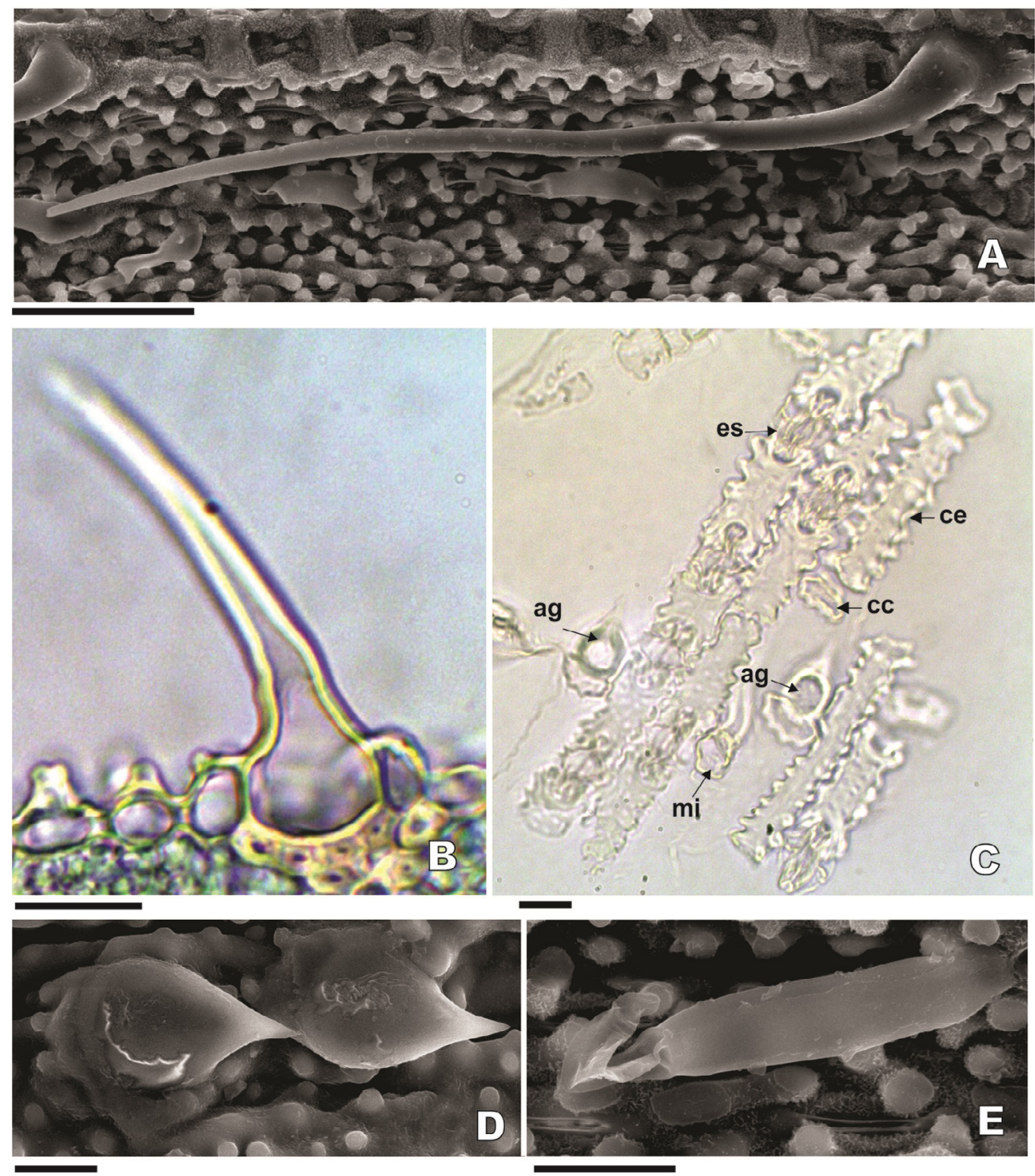

Fig. 5. Epidermis de las hojas de follaje de Bambusa. Macropelos, micropelos y aguijones. A-B: B. multiplex, epidermis de la cara abaxial. A: Macropelo (MEB, micromorfología). B: Macropelo (MO, corte transversal). C, D: B. tuldoides, epidermis de la cara abaxial. C: Aguijones, micropelos y células epidérmicas largas (MO, disociado). D: Aguijones, detalle (MEB, micromorfología). E: B. multiplex, epidermis de la cara abaxial, detalle de micropelo (MEB, micromorfología). Abreviaturas = ag: aguijón; cc: célula corta; ce: célula larga epidérmica; cl: célula clorenquimática; es: estoma. Escalas = A: $50 \mu \mathrm{m} ; \mathrm{B}-\mathrm{E}: 20 \mu \mathrm{m}$.

están a nivel de la epidermis y son más abundantes en la epidermis de la cara abaxial (Figs. 2C-H; 3A-F; 4B, F; 6B; 7A). El aparato estomático es paracítico (Figs. 4A; 5C) y se disponen en forma paralela al eje principal de la hoja, conformando líneas estomáticas en ambas superficies foliares (Fig. 3A-F).
En las tres especies de Bambusa se observan de 2 a 6 células buliformes, siendo la central más grande que las periféricas. Este grupo de células buliformes tiene forma de abanico y están localizadas en los valles de la epidermis de la cara adaxial de la lámina (Figs. 2A; 3B, D, F; 4G, H; 6A; 7A, B). 

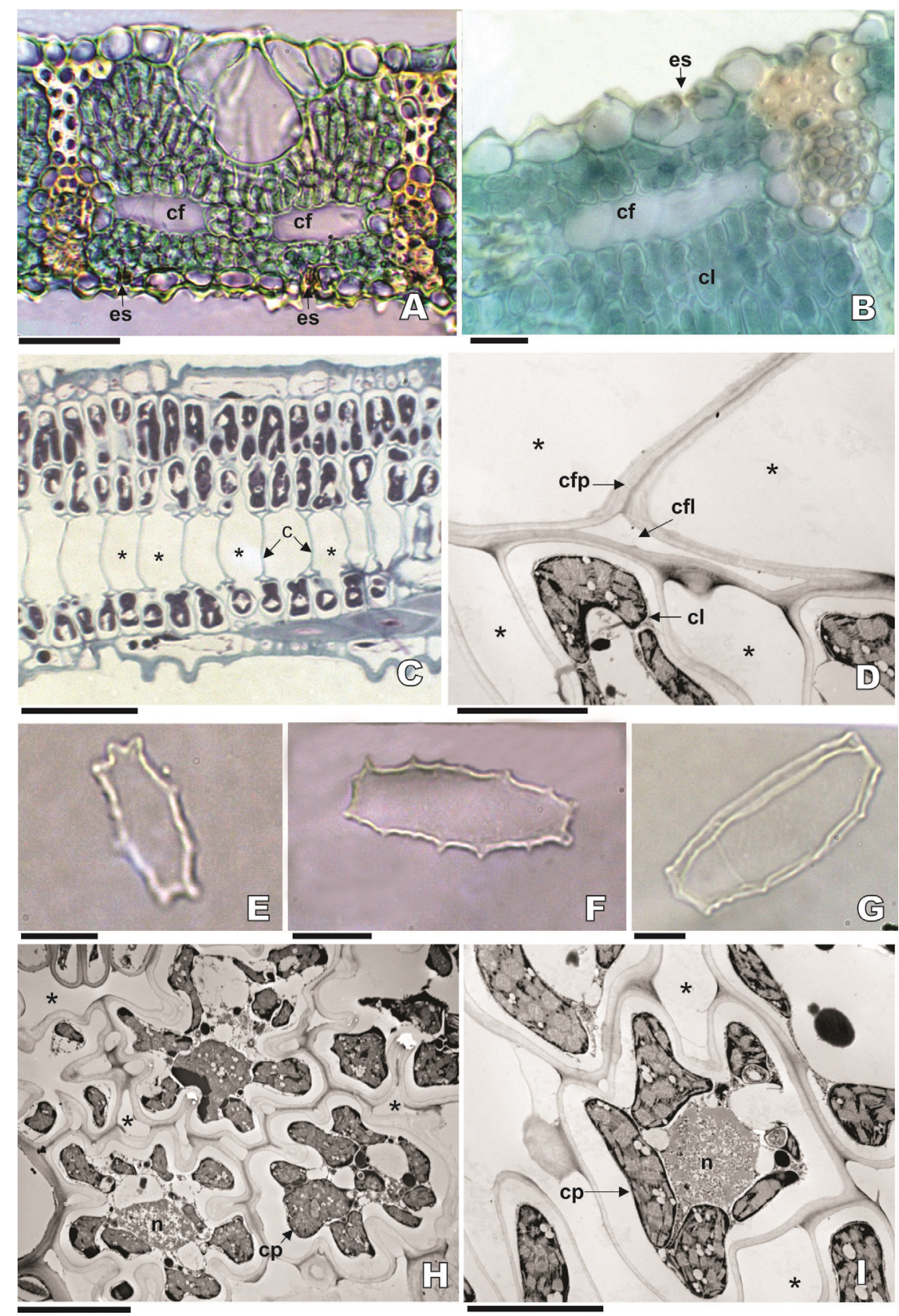

Fig. 6. Mesófilo de las hojas de follaje de Bambusa. A-G: Complejo "células fusoides". A, B: B. multiplex. A: Aspecto general (MO, corte transversal). B: Detalle (MO, corte transversal). C, D: B. tuldoides. C: distribución del complejo "células fusoides" (MO, corte longitudinal). D: Porción de célula fusoide (MET, corte longitudinal). E-G: Célula aislada del complejo "células fusoides" (MO, material disociado). E: $B$. multiplex. F: B. tuldoides. G: B. vulgaris cv. vittata. H-I: Células clorenquimáticas (en roseta) del mesófilo, $B$. tuldoides (MET, corte transversal). $\mathbf{H}$ : Aspecto general. I: Detalle de la célula clorenquimática. Abreviaturas = *: espacio intercelular; c: células del complejo "células fusoides"; cl: célula de mesófilo; cf: complejo "células fusoides"; cfl: lumen de la célula fusoide; cfp: pared de la células fusoide; $c p$ : cloroplastos de las células clorenquimáticas; n: núcleo de la célula clorenquimática. Escalas $=A, C: 50 \mu \mathrm{m} ; \mathrm{B}, \mathrm{H}: 10 \mu \mathrm{m}$; D: $5 \mu \mathrm{m}$; E-G: $20 \mu \mathrm{m}$; I: $5 \mu \mathrm{m}$. 


\section{F. Bessega et al. - Morfoanatomía de hojas de Bambusa}
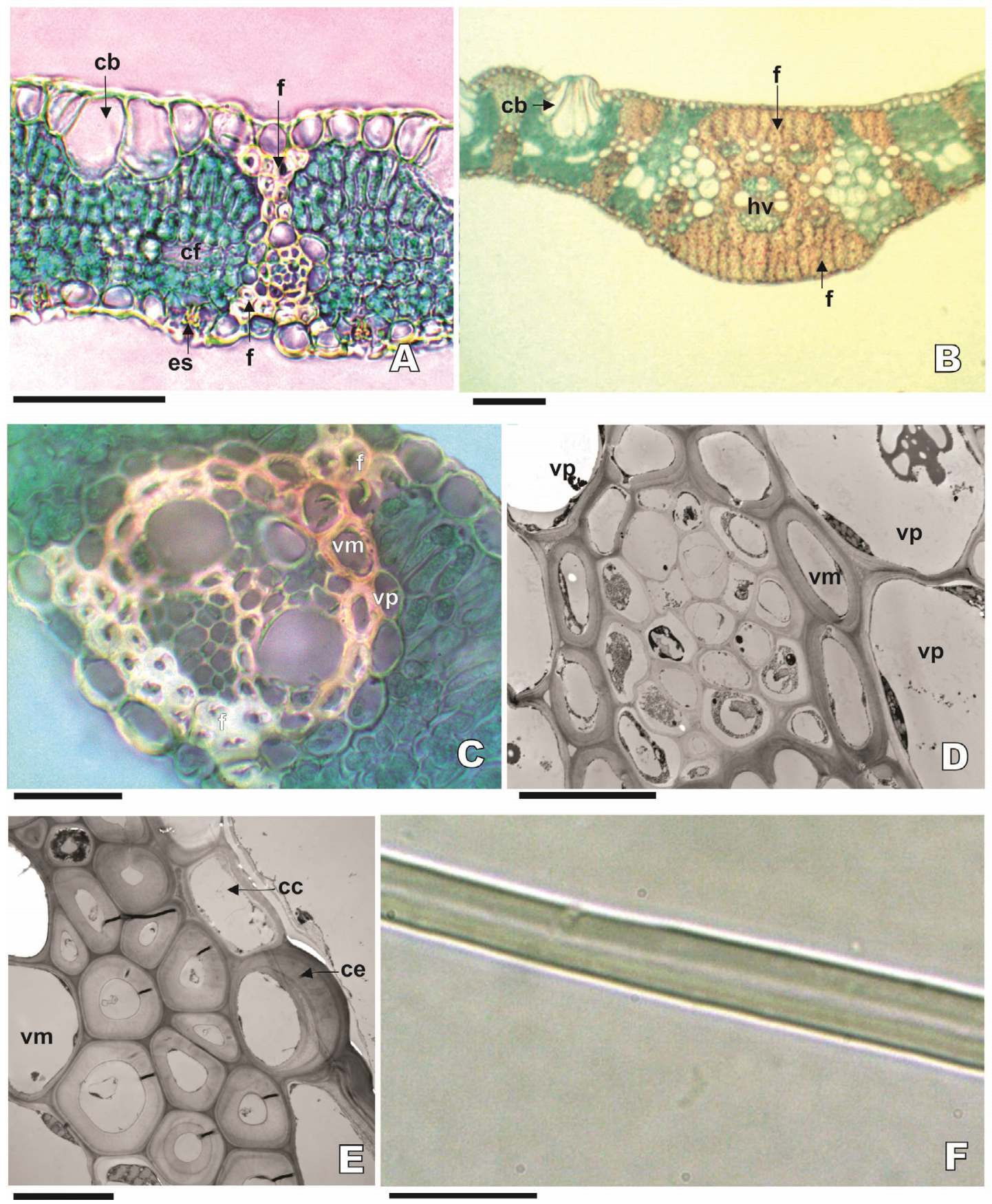

Fig. 7. Haces vasculares y fibras de las hojas de follaje de Bambusa. A-D, Haces vasculares: A-C: $B$. multiplex. A: Aspecto general (MO, corte transversal). B: Detalle haz principal (MO, corte transversal). C: Detalle de haz vascular menor o secundario (MO, corte transversal). D: B. tuldoides, detalle del haz vascular menor (MET, corte transversal). E-F: Fibras: E, B. tuldoides, detalle de fibras (MET, corte transversal). F: $B$. tuldoides, detalle de la pared y lumen de las fibras $(\mathrm{MO}$, material disociado). Abreviaturas $=\mathrm{cb}$ : célula buliforme; cc: célula corta; ce: célula larga epidérmica; cf: complejo "células fusoides"; es: estomas; f: fibra; hv: haz vascular; vm: vaina mestomática; vp: vaina parenquimática. Escalas $=A: 50 \mu \mathrm{m} ; \mathrm{B}: 100 \mu \mathrm{m} ; \mathrm{C}, \mathrm{F}$ : $20 \mu \mathrm{m} ; \mathrm{D}, \mathrm{E}: 10 \mu \mathrm{m}$ 
Tabla 2. Valores promedio de los parámetros cuantitativos (micrométricos) determinados en los cortes transversales de las hojas de Bambusa tuldoides, B. multiplex y $B$. vulgaris $\mathrm{cv}$. vittata. En cada fila, las letras distintas indican diferencias significativas entre especies para $\mathrm{P} \leq 0,05$ (Tukey).

\begin{tabular}{|lcccccc|}
\hline & B. multiplex & \multicolumn{2}{c}{ B.tuldoides } & B. vulgaris cv. vittata \\
\hline Espesor de la hoja, valle $(\mu \mathrm{m})$ & 103,77 & b & 112,03 & a & 98,73 & b \\
Espesor de la hoja, costilla $(\mu \mathrm{m})$ & 114,32 & b & 144,17 & a & 106,29 & c \\
Espesor epidermis de la cara adaxial $(\mu \mathrm{m})$ & 16,84 & b & 24,69 & a & 15,37 & c \\
Espesor epidermis de la cara abaxial $(\mu \mathrm{m})$ & 11,32 & b & 13,50 & a & 11,34 & b \\
Espesor cutícula de la superficie adaxial $(\mu \mathrm{m})$ & 2,36 & c & 3,36 & b & 5,04 & a \\
Espesor cutícula de la superficie abaxial $(\mu \mathrm{m})$ & 2,74 & b & 2,41 & c & 3,41 & a \\
Distancia intervenal $(\mu \mathrm{m})$ & 121,30 & b & 117,78 & b & 177,76 & a \\
Alto de la célula buliforme $(\mu \mathrm{m})$ & 45,23 & c & 50,23 & b & 55,25 & a \\
Ancho de la célula buliforme $(\mu \mathrm{m})$ & 33,84 & b & 35,44 & b & 37,63 & a \\
Número de células buliformes & 3,40 & a & 3,80 & a & 3,53 & a \\
Número de complejo "células fusoides" intervenal & 2,00 & a & 2,00 & a & 2,00 & a \\
\hline
\end{tabular}

Generalmente la célula buliforme central presenta un cristal, posiblemente, de sílice debido a la ausencia de birrefringencia con aplicación de luz polarizada (Fig. 4H). En el corte transversal de la hoja, generalmente, las células buliformes tienen forma de gota. Sin embargo, en B. tuldoides, también, se observan en forma de diamante o rombo.

Las tres especies muestran tricomas largos (macropelos), cortos (micropelos) y aguijones (Fig. 3A, C-F). Los macropelos son unicelulares y con paredes gruesas. La base de estos tricomas es amplia y está a nivel de la epidermis y el extremo es ahusado (Figs. 2G; 4G; 5A, B), Por otro lado, los micropelos están constituidos por dos células, la célula basal de pared gruesa y la célula distal de pared delgada. Ambas células tienen similitud en su forma, son estrechas o delgadas, tienen mayor longitud que ancho (Figs. 4F; 5C, E). Estos micropelos, cuando presentes, se distribuyen en la periferia del valle de la epidermis de la cara adaxial y en la epidermis de la superficie abaxial de la lámina (Fig. 3A, C-F). Los aguijones son robustos con bases anchas y extremo agudo (Figs. 2D, G; 4F; 5C, D). La superficie adaxial de B. multiplex es glabra (Fig. 3B). Bambusa multiplex y $B$. tuldoides comparten la presencia de micropelos, macropelos y aguijones en la epidermis de la superficie abaxial (Figs. 2G; 3A,
C, D; 5A-D). Por otro lado, la cara adaxial de $B$. tuldoides, solo presenta micropelos. En $B$. vulgaris $\mathrm{cv}$. vittata se pueden observar micropelos $\mathrm{y}$ aguijones en ambas superficies foliares, siendo más abundantes en la superficie abaxial (Figs. 3 E, F; 4F).

El mesófilo es homogéneo, no radiado, con pequeños espacios intercelulares, con células lobuladas vacuolizadas, de paredes delgadas y con abundantes cloroplastos (Figs. 2A, F, H; 4B, C, G, H; 6A-D, H, I; 7A, C). Bambusa tuldoides presenta células lobuladas en toda su superficie (Fig. 4B), mientras que B. multiplex exhibe células lobuladas asimétricamente hacia la cara abaxial (Figs. 4G; 7A, B). Ambos tipos de células son observadas en el mesófilo de $B$. vulgaris cv. vitatta (Figs. $2 \mathrm{~A} ; 4 \mathrm{H} ; 7 \mathrm{H}, \mathrm{I}$ ). Las células fusoides están dispuestas en hileras, con su eje principal perpendicular al eje principal de la hoja, intercaladas con espacios intercelulares o cavidades (Fig. 6C). En corte transversal de la lámina, se observa el largo y ancho de este complejo de células fusoides y espacios intercelulares ("células fusoides") (Figs. 2A, F; $4 \mathrm{~B}, \mathrm{G} ; 6 \mathrm{~A}, \mathrm{~B})$ y en el corte longitudinal de la lámina, se contempla el espesor de las células fusoides (Fig. 6C, D). Este complejo "célula fusoide" se aprecia en número de uno o dos, entre los haces vasculares, en la sección transversal 


\section{F. Bessega et al. - Morfoanatomía de hojas de Bambusa}

de la lámina. Cuando están en número de dos, se encuentran separadas entre sí por unas pocas células clorenquimáticas lobuladas (Figs. 2A; 6A, B). Las células fusoides de las tres especies en estudio exhiben una pared primaria delgada y sin presencia de organelas (Fig. 6 D-G). En el corte longitudinal de las hojas, se puede observar que éstas células son estrechas en su parte central y levemente dilatadas en la parte superior e inferior, tomando una forma de "I" (Fig. 6C, D). Mediante el análisis del material disociado de las hojas de $B$. multiplex, B. tuldoides y $B$. vulgaris $\mathrm{cv}$. vittata, se observa que las células fusoides aisladas muestran el borde sinuoso, producto de su contacto con las células lobuladas del mesófilo (Fig. 6E-G).

En el corte transversal de la nervadura principal de la hoja de las tres especies, se puede observar un haz vascular principal, dos menores hacia la cara adaxial y dos menores hacia la cara abaxial. La vena principal presenta la protuberancia sólo hacia la cara abaxial (Fig. 7B). Los haces vasculares son colaterales con vaina mestomática o esclerenquimática rodeada por una vaina parenquimática. La vaina mestomática está conformada por células elípticas esclerosadas. La vaina parenquimática presenta células elípticas, con presencia de cloroplastos escasos, similares a los observados en las células del mesófilo (Fig. 7C, D). Todos los haces vasculares presentan trabas esclerenquimáticas hacia las superficies epidérmicas. Las trabas que se extienden hacia la epidermis de la cara adaxial son estrechas o ligeramente dilatadas y están compuestas por una a varias hileras de fibras. Aquellas trabas que se extienden hacia la cara abaxial son más amplias, ensanchándose hacia la epidermis (Figs. 2A, 4G; 6A, 7A, B). No se observa tejido esclerenquimático en otras zonas del mesófilo. Las fibras que componen estas trabas tienen paredes gruesas, lisas y polilaminadas (Figs. 2B; 6B; 7E, F).

\section{Caracteres anatómicos cuantitativos (micrométricos)}

Bambusa tuldoides tiene los valles significativamente más profundos y las costillas más prominentes, respecto a las restantes especies estudiadas. Además, presenta mayor espesor de la hoja a nivel de los valles y de las costillas. El menor espesor de hoja a nivel de valles y costillas fue determinado en B. vulgaris cv. vittata (Tabla 2).
El análisis cuantitativo de los parámetros relacionados a la epidermis de las hojas de las especies de Bambusa analizadas indica que, $B$. tuldoides presenta ambas epidermis con espesor significativamente mayor que las restantes especies. Asimismo, el espesor de la cutícula en la superficie abaxial en esta especie es significativamente menor que en las otras dos especies. Bambusa vulgaris cv vittata comparte con B. multiplex similar espesor de las epidermis en ambas caras pero, B. vulgaris cv. vittata muestra la cutícula con mayor espesor significativo en ambas caras de la lámina (Tabla 2).

Considerando los parámetros cuantitativos determinados, las células buliformes significativamente más pequeñas se encuentran en $B$. multiplex. Las células de mayores dimensiones se observan en $B$. vulgaris cv. vittata, mostrando diferencias significativas con las restantes especies (Tabla 2).

En el material disociado, el registro de los parámetros micrométricos de las células fusoides aisladas mostró que $B$. multiplex tiene las células significativamente más pequeñas que las restantes especies. Mientras que, B. vulgaris cv. vittata exhibe las células de mayores dimensiones (Fig. 6E-G; Tabla 3).

Bambusa vulgaris cv. vittata se diferencia significativamente de las otras dos especies por tener la mayor distancia intervenal. Mientras que, Bambusa tuldoides y B. multiplex, no presentan diferencias significativas entre ellas para este parámetro (Tabla 2).

Los parámetros de las fibras de cada especie muestran que $B$. vulgaris cv. vittata presenta las fibras de mayor longitud, con diferencias significativas respecto a las restantes especies. Bambusa multiplex y B. tuldoides exhiben las fibras más cortas. Las fibras más anchas se registran en $B$. tuldoides, lo cual está asociado a los valores significativamente mayores del espesor de la pared (Fig. 7E, F; Tabla 3). Las fibras más estrechas son las de B. vulgaris cv. vittata con pared delgada, no presentando diferencias significativas con B. multiplex. Con respecto al diámetro del lumen no hay diferencias significativas entre las tres especies. Las fibras de $B$. vulgaris cv. vittata y $B$. tuldoides exhiben extremos más ahusados (Tabla 3 ). 
Tabla 3. Valores promedio de los parámetros cuantitativos (micrométricos) determinados en los disociados de las hojas de Bambusa tuldoides, $B$. multiplex y B. vulgaris cv. vittata: Células fusoides y fibras. En cada fila, las letras distintas indican diferencias significativas entre especies para $P \leq 0,05$

\section{(Tukey).}

\begin{tabular}{|c|c|c|c|c|c|c|}
\hline & \multicolumn{2}{|c|}{ B.multiplex } & \multicolumn{2}{|l|}{ B.uldoides } & \multicolumn{2}{|c|}{ B. vulgaris cv. vittata } \\
\hline \multicolumn{7}{|l|}{ Células fusoides } \\
\hline Largo $(\mu \mathrm{m})$ & 37,02 & c & 42,13 & $b$ & 59,52 & a \\
\hline Ancho $(\mu \mathrm{m})$ & 11,35 & c & 16,65 & $b$ & 20,81 & a \\
\hline Espesor $(\mu \mathrm{m})$ & 3,06 & $\mathrm{~b}$ & 3,84 & a & 4,25 & a \\
\hline \multicolumn{7}{|l|}{ Fibras } \\
\hline Longitud $(\mu \mathrm{m})$ & 600,08 & $\mathrm{~b}$ & 659,71 & $b$ & 778,45 & a \\
\hline Ancho $(\mu \mathrm{m})^{*}$ & 7,81 & $b$ & 8,66 & a & 7,34 & $\mathrm{~b}$ \\
\hline Espesor de la pared $(\mu \mathrm{m})^{*}$ & 3,14 & $\mathrm{~b}$ & 3,58 & a & 3 & $\mathrm{~b}$ \\
\hline Ancho del lumen $(\mu \mathrm{m})^{*}$ & 1,55 & a & 1,61 & a & 1,68 & a \\
\hline
\end{tabular}

Referencias. * mediciones determinadas en la parte media de la fibra.

\section{Discusión y Conclusiones}

A pesar de las diferencias en las dimensiones de las láminas en las especies estudiadas, las características morfológicas observadas y las dimensiones determinadas son coincidentes con aquellas informadas por otros autores para el género (Rúgolo de Agrasar \& Puglia, 2004; Sarma \& Pathak, 2004; Guerreiro, 2013; Lizarazu, 2013; Rúgolo, 2016a, b), como así también para otros géneros de bambúes leñosos (Londoño, 2002; Rúgolo de Agrasar \& Rodríguez, 2002, 2003; Bianco et al., 2004; Guerreiro \& Rúgolo de Agrasar, 2014). Estos autores utilizan principalmente los caracteres caulinares para la identificación de distintas entidades. Sólo Sarma \& Pathak (2004) diferenciaron varias especies de Bambusa mediante el uso de características morfológicas foliares, pero no tratan las tres especies analizadas.

La anatomía de las tres especies del genero Bambusa estudiadas concuerda con la anatomía tipo de la subfamilia Bambusoideae y en general, a la familia Poaceae: células silíceas y suberosas (células cortas), tricomas bicelulares (micropelos) y unicelulares (macropelos), aguijones, células epidérmicas papilosas y la forma de estomas (Metcalfe, 1960; Ellis, 1976, 1979; Motomura et al., 2004; Rúgolo \& Puglia, 2004; Desai \& Raole, 2013;
Lizarazu, 2013; Leandro et al., 2016, 2017, 2020; Liana et al., 2017). Actualmente, estos resultados son noveles para estas especies en estudio, ya que otros autores que estudiaron bambúes leñosos no han abordado este tipo de caracterización, principalmente sobre la base de caracteres micrométricos. Solo Márquez et al. (2011) indicaron diferencias entre Guadua angustifolia y G. amplexifolia dadas por determinados datos cuantitativos.

Según lo expresado por Zhang et al. (2014), la distribución y número de papilas de las células epidérmicas alrededor del estoma de $B$. multiplex, $B$ tuldoides y $B$. vulgaris cv. vittata pueden describirse como del tipo IV (4 a 10 papilas alargadas rodeando los estomas formando cámara supraestomática) para la epidermis de la cara adaxial y tipo III ( 4 a 8 papilas alargadas rodeando a los estomas sin formar cámara supraestomática) para la epidermis de la cara abaxial. Por otro lado, Yang et al. (2008) encontraron 4 papilas rodeando las células oclusivas en Bambusa multiplex, $B$. chungii y $B$. surrecta. Sin embargo, Liana et al. (2017) encontraron en $B$. blumeana 2 papilas, en $B$. maculata 5 papilas, en $B$. striata 3 papilas y en $B$. vulgaris 4 papilas por aparato estomático. En todos los casos las papilas generalmente son simples, tal como se observó en las tres especies estudiadas. Raramente, se observan papilas ramificadas en la epidermis abaxial de $B$. tuldoides. El número, la forma 


\section{F. Bessega et al. - Morfoanatomía de hojas de Bambusa}

y la distribución de las papilas en las células anexas a los estomas de Bambusa y otros representantes de bambúes leñosos presentan patrones regulares que se pueden aplicar en la taxonomía a nivel de género (Wang et al., 2002; Guerreiro et al., 2013; Lizarazu, 2013; Leandro et al., 2016, 2020). Sin embargo, se ha informado que, a pesar que se observan estos caracteres epidérmicos en otros géneros de bambúes leñosos, son poco relevantes para diferenciar taxones (Márquez et al., 2011). Además, respecto a las células epidérmicas de ambas superficies foliares de las tres especies en estudio, se observó que son largas con pared onduladas en vista superficial. Bambusa blumeana, B. maculata, B. striata y B. vulgaris exhiben estos caracteres en sus células epidérmicas (Yang et al., 2008; Liana et al., 2017). Sin embargo, se ha reportado el borde recto de estas células en $B$. tuldoides (Guerreiro et al., 2016).

En la epidermis de la cara abaxial de las tres especies en estudio, se observan dos tipos de células silíceas: unas de contorno cuadrangular con su parte media menos estrecha y otras con la parte media muy angosta. Estos tipos de células cortas han sido clasificadas como tipo I y tipo II respectivamente para los géneros Bambusa y Guadua (Londoño \& Kobayashi, 1991). En la epidermis de la cara adaxial solo se encuentran las células silíceas de tipo II. Estos caracteres, no coinciden con lo informado por Guerreiro et al. (2016) en Bambusa tuldoides, donde las células silíceas son solo rectangulares. Otras especies del género Bambusa (B. blumeana, B. maculata, B. striata y B. vulgaris) exhiben las mismas características de las células silíceas (Yang et al., 2008; Liana et al., 2017) que aquellas observadas en las especies en estudio. Por otro lado, Londoño \& Kobayashi (1991), concluyeron que el tamaño y la distribución de células silíceas, independientemente de la forma, se puede utilizar como caracteres diagnósticos para diferenciar los géneros Bambusa y Guadua.

Las dimensiones de las células buliformes exhiben diferencias entre las especies analizadas. La forma, el tamaño y la disposición de las células buliformes se pueden utilizar para fines de clasificación e identificación taxonómica (Vieira et al., 2002; Leandro et al., 2016; Liana et al., 2017). Montiel et al. (2006a, d) reportan que Guadua angustifolia presenta células buliformes pequeñas y $G$. macclurei células buliformes grandes, desde un punto de vista cualitativo y no cuantitativo.
La epidermis de la cara adaxial glabra de $B$. multiplex es similar a lo observado en Guadua paraguayana y Merostachys clausenii (Lizarazu, 2013) y en especies de Chusquea (Leandro et al., 2017). Por otro lado, la epidermis de la cara adaxial de $B$. tuldoides, solo presenta micropelos, tal como lo observó Lizarazu (2013) para otras especies y géneros de bambúes leñosos. Las 97 especies de la subfamilia Bambusoideae estudiadas por Zhang et al. (2014) presentan micropelos en los valles de la epidermis adaxial, incluida $B$. ventricosa. La epidermis de la cara abaxial de $B$. multiplex y B. tuldoides comparten la presencia de micropelos, macropelos y aguijones, coincidiendo con otras especies de bambúes como Chusquea tenella, Colanthelia cingulata, Guadua paraguayana, Merostachys multiramea y $M$. skvortzovii (Lizarazu, 2013). Zhang et al. (2014) informan que $B$. ventricosa no presenta macropelos en la superficie abaxial de la lámina.

Liana et al. (2017) analizaron la epidermis de $B$. blumeana, B. maculata, B. striata y B. vulgaris y encontraron aguijones en la cara abaxial y micropelos en ambas superficies foliares. Asimismo, informaron que solo en $B$. vulgaris, los aguijones están en la epidermis de ambas caras de la lámina, coincidiendo con la observación realizada en este estudio para $B$. vulgaris cv. vittata y B. tuldoides. Zhang et al. (2014) determinaron que hay aguijones en ambas caras de la lámina de $B$. ventricosa. La presencia de aguijones ha sido reportada para otros géneros y especies de bambúes leñosos (Montiel et al., 2006b, d; Montiel \& Sánchez, 2006; Márquez et al., 2011; Guerreiro \& Rúgolo de Agrasar, 2014).

Lascélulasdelmesófilolobuladashansidodescriptas en otras especies de la subfamilia Bambusoideae (Metcalfe, 1960; Calderón \& Soderstrom, 1973; Soderstrom \& Ellis, 1988; Londoño, 2002; Leandro et al., 2016) y la organización no radial de estas células se diferencia del mesófilo radial presente, por lo general, en las Poaceae (Londoño, 2002; Bianco et al., 2004). Por el contrario, el mesófilo homogéneo no está presente en todas las especies de bambúes, por ejemplo Márquez et al. (2011) describe un mesófilo isofacial y no radiado en especies de Guadua. Otro carácter propio de las Bambusoideae es la presencia de extensiones esclerenquimáticas hacia ambas superficies foliares, relacionados a los haces vasculares y las vainas mestomática y parenquimática. Estos caracteres han sido observados en especies nativas y exóticas de la Argentina, incluyendo a 
representantes de Bambusa (Metcalfe, 1960; Londoño, 2002; Motomura et al., 2004; Márquez et al., 2011; Guerreiro, 2013; Lizarazu, 2013; Guerreiro et al., 2016; Leandro et al., 2016).

Numerosos autores mencionan que las células fusoides, también, es una característica relevante de la subfamilia Bambusoideae y sus representantes (Metcalfe, 1960; Clark, 1991; Judziewicz et al., 1999; Motomura, et al., 2000; Londoño, 2002; Bianco et al., 2004; Guerreiro et al., 2011; March \& Clark, 2011; Guerreiro et al., 2013; Lizarazu, 2013; Guerreiro \& Rúgolo de Agrasar, 2014; Guerreiro et al., 2016; Vega et al., 2016; Leandro et al., 2017). Las Bambusoideae eran interpretadas como un grupo monofilético basado en la presencia de células fusoides. Sin embargo, se ha comprobado la presencia de estas células en otros taxones de Poaceae, como Anomochlooideae, Pharoideae, Puelioideae, y algunos miembros de Pooideae y Oryzoideae. Por lo cual, la presencia de este tipo células es una plesiomorfia dentro de Poaceae (Vega et al., 2016; Leandro et al., 2018, 2020). A la madurez de la hoja, las células fusoides exhiben la forma de "I" intercaladas con espacios intercelulares amplios. Vega et al. (2016) indican que, durante la ontogenia de la hoja, las células fusoides se plasmolizan y colapsan dejando un espacio intercelular amplio entre ellas. Por otro lado, Leandro et al. (2018) informa que los espacios intercelulares entre las células fusoides son producto de la lisis de una o varias células fusoides, por lo cual considera que son cavidades entre dichas. Independientemente de su origen, son espacios intercelulares entre las células fusoides colapsadas en forma de "I". Por tal motivo, cuando los diferentes autores, mencionados al principio del párrafo, analizan las "células fusoides" en corte transversal de la lámina, están describiendo el complejo de células y espacios intercelulares. Sólo en el corte longitudinal de la lámina es posible visualizar concretamente los componentes de dicho complejo, ya que se disponen en forma perpendicular al eje principal de la hoja (Wu, 1973; Vega et al., 2016; Leandro et al., 2018).

Es de destacar que en el presente estudio no solo se analiza el complejo "células fusoides" en cortes transversales y longitudinales de las hojas, sino que las células han sido aisladas en material disociado de la lámina. Esto ha permitido determinar las dimensiones de las células fusoides, siendo un resultado novel y demostrando que existen diferencias entre las tres especies de Bambusa estudiadas. La forma $\mathrm{y}$ el tamaño de estas células son características que pueden delimitar las especies dentro de la subfamilia Bambusoideae (Leandro et al., 2016) y para establecer relaciones filogenéticas dentro de la Familia Poaceae (Leandro et al., 2018, 2020). Varios autores han reportado diversas funciones del complejo "células fusoides" relacionadas a la conducción simplástica del agua desde los haces vasculares a las células del mesófilo y a la translocación y distribución de fotoasimilados entre el mesófilo y los haces vasculares (Vieira et al., 2002; Wang et al., 2016); al almacenamiento de $\mathrm{CO} 2$ y en mecanismo de reflectancia intra- o intercelular de la luz (March \& Clark, 2011); al mantenimiento de la arquitectura interna de la hoja extendida adulta (Vega et al., 2016); a la síntesis y el almacenamiento de los gránulos de almidón en las primeras etapas de desarrollo de la hoja (Leandro et al., 2018).

Las fibras de las hojas de B. vulgaris cv vittata, presentan menor ancho en la parte media y menor espesor de pared respecto a las otras dos especies de Bambusa. Además, con respecto al extremo de las fibras, $B$. vulgaris $\mathrm{cv}$. vittata y $B$. tuldoides comparten el carácter de extremo ahusado. Estos caracteres observados son compatibles con aquellos de las fibras de los culmos de las mismas especies (Yormann, 2017; Yormann et al., 2020).

Se ha comprobado que los estudios de la anatomía foliar en los bambúes leñosos tienen valor taxonómico en la diferenciación de las especies, con mayor relevancia a nivel genérico (Prat, 1960; Vieira et al., 2002; Montiel et al., 2006a, b, c, d; Guerreiro et al., 2011, 2016; Márquez et al., 2011; Desai \& Raole, 2013; Lizarazu, 2013; Guerreiro \& Rúgolo de Agrasar, 2014; Leandro, et al., 2016, 2017; Liana et al., 2017). La anatomía foliar sirve para diferenciar la subfamilia Bambusoideae del resto de las Poaceae y definir las tribus y subtribus (Ellis, 1987; Soderstrom \& Ellis, 1988; Londoño, 2002; Leandro et al., 2020). Respecto al género Bambusa, Soderstrom \& Ellis (1988) indican caracteres diagnósticos para las tres especies de Bambusa abordadas en el presente estudio como, micropelos bicelulares, mesófilo no radiado, presencia de células fusoides y células lobuladas en el mesófilo, más de un haz vascular superpuestos en la nervadura central y cuerpos silíceos.

El análisis integral anatómico de las hojas de follaje de B. multiplex, B. tuldoides y $B$. vulgaris $\mathrm{cv}$. vittata, mediante parámetros cualitativos (Tabla 4) y cuantitativos (Tabla 1-3), ha permitido identificar 


\section{F. Bessega et al. - Morfoanatomía de hojas de Bambusa}

características diagnósticas del género y obtener caracteres propios de cada especie. Este estudio descriptivo puede ser aplicado a investigaciones sobre la variación intraespecífica del género Bambusa considerando diferentes áreas geográficas. Por otro lado, el empleo de la técnica de material disociado en el marco de metodologías integrales de anatomía vegetal, resulta interesante para estudiar cuali y cuantitativamente los diferentes tipos celulares de la hoja, con el fin de proveer una nueva herramienta para estudios sistemáticos y filogenéticos.

Tabla 4. Caracteres cualitativos de la anatomía y micromorfología de las hojas de follaje comparativos entre Bambusa tuldoides, B. multiplex y B. vulgaris cv. vittata.

\begin{tabular}{|c|c|c|c|c|c|c|}
\hline \multirow[b]{2}{*}{ EPIDERMIS } & \multicolumn{2}{|c|}{ Bambusa multiplex } & \multicolumn{2}{|c|}{ Bambusa tuldoides } & \multicolumn{2}{|c|}{$\begin{array}{l}\text { Bambusa vulgaris } \\
\text { cv. vittata }\end{array}$} \\
\hline & abaxial & adaxial & abaxial & adaxial & abaxial & adaxial \\
\hline \multicolumn{7}{|c|}{ Papilas de las células anexas del aparato estomático } \\
\hline número por estoma & 8 & $4-8$ & 8 & $4-8$ & 4- 8 & $4-8$ \\
\hline forma simple & $\mathrm{x}$ & $x$ & $x$ & $x$ & $\mathrm{x}$ & $\mathrm{x}$ \\
\hline forma ramificada & - & - & $\begin{array}{c}\mathrm{x} \\
\text { (raramente) }\end{array}$ & - & - & - \\
\hline fusionadas & $x$ & $x$ & - & - & - & $\mathrm{x}$ \\
\hline tipo ${ }^{(a)}$ & III & IV & III & IV & III & IV \\
\hline \multicolumn{7}{|l|}{ Células cortas silíceas } \\
\hline forma cuadrangular (tipo 1$)^{(\mathrm{b})}$ & $x$ & - & $x$ & - & $x$ & - \\
\hline forma de clava (tipo) ${ }^{(b)}$ & $x$ & $x$ & $x$ & $x$ & $x$ & $x$ \\
\hline \multicolumn{7}{|l|}{ Tricomas } \\
\hline micropelos & $x$ & - & $x$ & $x$ & $x$ & $x$ \\
\hline macropelos & $x$ & - & $x$ & - & $x$ & $x$ \\
\hline aguijones & $x$ & - & $x$ & - & $x$ & $x$ \\
\hline \multicolumn{7}{|l|}{ Células buliformes } \\
\hline a nivel de epidermis & - & $x$ & - & $x$ & - & - \\
\hline sobre nivel de la epidermis & - & - & - & - & - & $x$ \\
\hline forma (célula principal) & - & gota & - & romboédrica & - & gota \\
\hline \multicolumn{7}{|l|}{ CELULAS CLORENQUIMATICAS del mesófilo } \\
\hline forma lobulada en roseta & & - & & $x$ & & x \\
\hline $\begin{array}{l}\text { forma lobulada asimétricamente hacia la cara } \\
\text { abaxial }\end{array}$ & & $x$ & & - & & $x$ \\
\hline $\begin{array}{l}\text { forma lobulada asimétricamente hacia la cara } \\
\text { adaxial }\end{array}$ & & - & & - & & - \\
\hline \multicolumn{7}{|l|}{ ESCLERÉNQUIMA en el mesófilo } \\
\hline fibras en zona intercostal (valle) & & - & & - & & - \\
\hline fibras en zona costal (costilla) & & $x$ & & $x$ & & $x$ \\
\hline traba esclerenquimática hacia cara adaxial & column & ar o linear & columne & ar o linear & column & ro linear \\
\hline traba esclerenquimática hacia cara abaxial & & tada & dila & tada & dila & tada \\
\hline trabas esclerenquimática prominentes & & - & & $x$ & & - \\
\hline
\end{tabular}

Referencias. (a) tipos de distribución de papilas en cada aparato estomático, según Zhang et al. (2014): III, 4 a 8 papilas alargadas rodeando a los estomas sin formar cámara supraestomática; IV, 4 a 10 papilas alargadas rodeando los estomas formando cámara supraestomática.(b) tipos de células cortas silíceas, según Londoño y Kovayashi (1991). Abreviaturas: (x) indica presencia del carácter y el guión (-) ausencia. 


\section{ConTribución de AUtores}

Todas las autoras contribuyeron en el diseño, realización de la investigación e interpretación de los datos así como la redacción del manuscrito. GY y FB intervinieron en la colección de las muestras. NA y FB diseñaron y concretaron las figuras y tablas.

\section{Agradecimientos}

A los técnicos de los Servicios de Microscopía Electrónica, Lic. Fabián Tricárico (Microscopía Electrónica de Barrido, MACN Bernardino Rivadavia, CABA, Buenos Aires) y Dra. Susana Jurado (Microscopía Electrónica de Transmisión, FCVUNLP, La Plata, Buenos Aires) por su disposición $\mathrm{y}$ atención. Al CIN por el otorgamiento de Becas al Estímulo a las Vocaciones Científicas (EVC), mediante las cuales se enmarco este trabajo. Al Departamento de Ciencias Básicas de la Universidad Nacional de Luján por el financiamiento provisto anualmente para investigación, a cargo de la Dra. Nancy M. Apóstolo.

\section{Bibliografía}

ALEGRÍA OLIVERA, J. J., C. I. GUERREIRO \& A. S. VEJA. 2017. Two new species of Chusquea subg. Magnifoliae (Poaceae, Bambusoideae, Chusqueinae) from Peru. Syst. Bot. 42: 807-816. http://dx.doi.org/10.1600/036364417X696447

BAMBOO BIODIVERSITY WEBSITE IOWA STATE UNIVERSITY. 2021. Bamboo diversity. [online]. Disponible en: https:// www.eeob.iastate. edu/research/bamboo/characters/ anatomy.html [Acceso: 1 Octubre 2021].

BIANCO, C. A., T. A. KRAUS \& A. C. VEGETTI. 2004. La hoja en las Liliópsidas. En: La hoja. Morfología y anatomía. Universidad Nacional de Río Cuarto (Ed.). $1^{\circ}$ edición. Pp: 89- 120. Río Cuarto, Córdoba, Argentina.

CALDERÓN, C. E. \& T. R. SODERSTROM. 1973. Morphological and anatomical considerations of the grass subfamily Bambusoideae based on the new genus Maclurolyra. Sm. C. Bot. 11: 1-55. http://dx.doi.org/10.5962/bhl.title. 123240

CLAYTON, W. D. \& S. A. RENVOIZE. 1986. Genera Graminum, grasses of the world. Kew Bull. Addit. Ser. XIII. Her Majesty'Stationery Office, London.
D’AMBROGIO, A. M. 1986. Manual de técnicas en histología vegetal. Editorial Hemisferio Sur. Buenos Aires, Argentina.

DESAI, R. J. \& V. N. RAOLE. 2013. Leaf micromorphological studies in subfamily Bambusoideae and Pooideae from Gujarat, India. Kathamandu Univ. J. Sci. Eng. Technol. 9: 37-47.

ELLIS, R. P. 1976. A procedure for standardizing comparative leaf anatomy in the Poaceae. I- The leafblade as viewed in transverse section. Bothalia 12: 65-109. http://dx.doi.org/10.4102/abc.v12i1.1382

ELLIS, R. P. 1979. A procedure for standardizing comparative leaf anatomy in the Poaceae. II- The epidermis as seen in surface view. Bothalia 12: 641671. http://dx.doi.org/10.4102/abc.v12i4.1441

ELLIS, R. P. 1987. A review of comparative leaf blade anatomy in the systematics of Poaceae: the past twenty-five years. En: SODERSTROM, T.R., HILU, K.W., CAMPBELL, C.S. \& BARKWORTH, M.E. (Eds.) Grass Systematics and Evolution. Pp: 3-10. Smithsonian Institution Press. Washington D.C., USA.

GHOSH, S. S. \& B. S. NEGI. 1959. Anatomical of Indian bamboo: Part I. Epidermal features of Bambusa arundinacea Willd., B. polymorpha Munro, B. vulgaris Schrad., Dendrocalamus membranaceus Munro, D. strictus Nees, and Melocanna bambusoides Trin. Indian Foresters 86: 719-727.

GROSSER, D. \& W. LIESE. 1971. On the anatomy of Asian bamboos with special reference to their vascular bundles. Wood Sci. Technol. 5: 290-312. https://doi.org/10.1007/BF00365061

GUERREIRO, C. I. 2013. Bambúes leñosos (Poaceae: Bambusoideae:Bambuseae) Análisis fenológico de los bambúes leñosos nativos y exóticos de América austral, con la aplicación de estudios ecológicos, sistemáticos, morfológicos y anatómicos. Tesis doctoral. Facultad de Ciencias Exactas, Universidad de Buenos Aires. Argentina.

GUERREIRO, C. \& Z. RÚGOLO DE AGRASAR. 2014. Revalidation of Chusquea argentina (Poaceae, Bambusoideae, Bambuseae) on the basis of morphological, anatomical and phenological characters. Phytotaxa 158: 265-274. http://dx.doi.org/10.11646/phytotaxa.158.3.6

GUERREIRO, C., Z. E. RÚGOLO DE AGRASAR \& M. F. RODRÍGUEZ. 2011. Novedades en Chusquea deficiens (Poaceae, Bambusoideae, Bambuseae), un bambú muy poco conocido del noroeste argentino. Bol. Soc. Argent. Bot. 46: 177-185. 


\section{F. Bessega et al. - Morfoanatomía de hojas de Bambusa}

GUERREIRO, C., Z. E. RÚGOLO DE AGRASAR \& M. F. RODRIGUEZ. 2013. A contribution to the identification of vegetative Andean woody bamboos in southernmost America using leaf anatomy. $J$. Torrey Bot. Soc. 140: 259-268.

http://dx.doi.org/10.3159/TORREY-D-12-00065.1

GUERREIRO, C., M. F. RODRÍGUEZ \& Z. E. RÚGOLO. 2016. Caracteres anatómicos: anatomía foliar y caulinar. En: RÚGOLO, Z.E. (Ed.) Bambúes leñosos nativos y exóticos de la Argentina. $1^{\mathrm{a}}$ Edición. Pp: 45-65. Hurlingham, Buenos Aires, Argentina.

HERRERA-GIRALDO, C., M. GÓMEZ-BARRERA, M. SAAVEDRA HERNANDEZ, G. FONTHAL RIVERA, V. E. GONZÁLEZ CEVALLOS \& H. ARIZA CALDERÓN. 2009. Cuantificación de sílice en el follaje de Guadua angustifolia del Departamento de Quindío. Revista Investigaciones Universidad del Quindío 19: 14-17.

JUDZIEWICZ, E. J., L. G. CLARK, X. LONDOÑO \& M. G. STERN. 1999. American bamboos. Smithsonian Institution Press, Washington D.C., USA. https://doi.org/10.2307/2666622

KELCHNER, S. A. \& BAMBOO PHYLOGENY GROUP. 2013. Higher level phylogenetic relationships within the bamboos (Poaceae: Bambusoideae) based on five plastid markers. Mol. Phylogenet. Evol. 67: 404-413. http://dx.doi.org/10.1016/j.ympev.2013.02.005

LEANDRO, T. D., R. T. SHIRASUNA, T. S. FILGUEIRAS \& V. L. SCATENA. 2016. The utility of Bambusoideae (Poaceae, Poales) leaf blade anatomy for identification and systematics. Braz. J. Biol. 76: 708-717. http://dx.doi.org/10.1590/1519-6984.01715

LEANDRO, T. D., V. L. SCATENA \& L. G. CLARK. 2017. The contribution of foliar micromorphology and anatomy to the circumscriptions of species within the Chusquea ramosissima informal group (Poaceae, Bambusoideae, Bambuseae). Plant Syst. Evol. 303: 745-756.

http://dx.doi.org/10.1093/aob/mcy025

LEANDRO, T. D., T. M. RODRIGUES, L. G. CLARK. \& V. L. SCATENA. 2018. Fusoid cells in the grass family Poaceae (Poales): a developmental study reveals homologies and suggests new insights into their functional role in young leaves. Ann. Bot. 122: 833-848. http://dx.doi.org/10.1093/aob/mcy025

LEANDRO, T. D., V.L. SCATENA \& K. G. CLARK. 2020. Comparative leaf blade anatomy and micromorphology in the systematics and phylogeny of Bambusoideae (Poaceae: Poales). Bot. J. Linn. Soc. 192: 165-183.

https://doi.org/10.1093/botlinnean/boz074

LIANA, A., PURNOMO, I. SUMARDI. \& B. S. DARYONO. 2017. The classification of Bambusa spp. from Celebes based on the micromorphological characters of leaf epidermis. J. Trop. Life Sci. 7: 197-203. http://dx.doi.org/10.11594/jtls.07.03.02

LIESE, W. 1998. The anatomy of bamboo culms. Technical Report 18. International Network of Bamboo and Rattan, Beijing, China.

LIZARAZU, M. A. 2013. Bambúes leñosos (Poaceae: Bambusoideae:Bambuseae) del Noreste argentino y regiones limítrofes: estudios taxonómicos, morfológicos, anatómicos y biogeográficos. Tesis Doctoral. Facultad de Ciencias Exactas y Naturales. Universidad de Buenos Aires. Argentina.

LONDOÑO, X. 2002. Distribución, morfología, taxonomía, anatomía, silvicultura y uso de los bambúes del Nuevo Mundo. Cátedra de Maestría en Construcción: modulo Guadua. Universidad Nacional de Colombia, Bogotá.

LONDOÑO, X. \& M. KOBAYASHI. 1991. Estudio comparativo entre los cuerpos silíceos de Bambusa y Guadua. Caldasia 16: 407-417. http://dx.doi.org/10.15446/caldasia

MARCH, R. H. \& L. G. CLARK. 2011. Sun-shade variation in bamboo (Poaceae: Bambusoideae) leaves. Telopea 13: 93-104. http://dx.doi.org/ 10.7751/telopea20116007

MÁRQUEZ, L., M. GARCÍA \& D. MARÍN. 2011. Anatomía foliar de Guadua angustifolia Kunth, $G$. amplexifolia Presl. y Elytrostachys typica McClure (Poaceae, Bambusoideae). Ernstia 21: 91-109.

MEJÍA, G. A. I., C. C. GALLARDO, J. J. VALLEJO, L. G. RAMÍREZ, E. C. ARBOLEDA, A. E. S. DURANGO, Y.F.A. JARAMILLO. \& E. CADAVID. 2009. Plantas del género Bambusa: importancia y aplicaciones en la industria farmacéutica, cosmética y alimentaria. Vitae (Revista de la Facultad de Química Farmacéutica) 16: 396-405.

METCALFE, C. R. 1960. Anatomy of the Monocotyledons. I. Gramineae. Oxford Clarendon, Oxford, Inglaterra. https://doi.org/10.1126/science.133.3467.1817-a

MONTIEL, M., V. M. JIMÉNEZ \& E. GUEVARA. 2006a. Caracterización anatómica ultraestructural de las variantes "atlántica", "sur" y "cebolla" del bambú Guadua angustifolia (Poaceae, Bambusoideae), en Costa Rica. Rev. Biol. Trop. (Int. J. Trop. Biol.) 54: 1-12. https://doi.org/10.15517/RBT.V54I1.26854 
MONTIEL, M., V. M. JIMÉNEZ \& E. GUEVARA. 2006b. Ultraestructura del bambú Guadua angustifolia var. bicolor (Poaceae, Bambusoideae), presente en Costa Rica. Rev. Biol. Trop. (Int. J. Trop. Biol.) 54: 13-19. https://doi.org/10.15517/RBT. V54I1.26855

MONTIEL, M., V. M. JIMÉNEZ \& E. GUEVARA. 2006c. Ultraestructura del bambú Guadua macclurei (Poaceae, Bambusoideae) de Costa Rica. Rev. Biol. Trop. (Int. J. Trop. Biol.) 54: 35-42. https://doi.org/10.15517/RBT.V54I1.26858

MONTIEL, M., V. M. JIMÉNEZ \& E. GUEVARA. 2006d. Ultraestructura del bambú Guadua amplexifolia (Poaceae - Bambusoideae) presente en Costa Rica. Rev. Biol. Trop. (Int. J. Trop. Biol.) 54: 21-28. https://doi.org/10.15517/RBT.V54I1.26856

MONTIEL, M \& E. SÁNCHEZ. 2006. Ultraestructura de bambúes del género Dendrocalamus (Poaceae: Bambusoideae) cultivados en Costa Rica I: Dendrocalamus latiflorus. Rev. Biol. Trop. (Int. J. Trop. Biol.) 54: 43- 50.

https://doi.org/10.15517/RBT.V54I1.26859

MOTOMURA, H., T. FUJII. \& M. SUZUKI. 2000. Distribution of silicified cells in the leaf blades of Pleioblastus chino (Franchet et Savatier) Makino (Bambusoideae). Ann. Bot. 85: 751-757. http:// dx.doi.org/10.1006/anbo.2000.1124

MOTOMURA, H., T. FUJII \& M. SUZUKI. 2004. Silica deposition in relation to ageing of leaf tissues in Sasa veitchii (Carriere) Rehder (Poaceae: Bambusoideae). Ann. Bot. 93: 1-14. http://dx.doi.org/10.1093/aob/mch034

RÚGOLO, Z. E. 2016a. Bambusoideae Luerss. En: RÚGOLO, Z.E. (ed.). Bambúes leñosos nativos $y$ exóticos de Argentina. $1^{\circ}$ edición. Pp. 13-18. Hurllingham, Buenos Aires, Argentina.

RÚGOLO, Z. E. 2016b. Bambúes leñosos exóticos. En: RÚGOLO, Z.E. (ed.). Bambúes leñosos nativos $y$ exóticos de Argentina. $1^{\circ}$ edición. Pp. 125-166. Hurllingham, Buenos Aires, Argentina.

RÚGOLO DE AGRASAR, Z. E. \& M. L. PUGLIA. 2004. Gramineas ornamentales. Volumen I. LOLA Ediciones. Buenos Aires, Argentina.

RÚGOLO DE AGRASAR, Z. E. \& M. F. RODRÍGUEZ. 2002. Cauline anatomy of native Woody bamboos in Argentina and neighbouring areas: Epidermis. Bot. J. Linn. Soc. 1381: 45-55. http://dx.doi.org/10.1046/j.1095-8339.2002.00004.x RÚGOLO DE AGRASAR, Z. E. \& M. F. RODRÍGUEZ. 2003. Culm anatomy of native Woody bamboos in
Argentina and neighboring areas: Cross section. Bamboo Sci. Cult. (J. Am. Bamboo Soc.) 17: 28-43. SARMA, K. K. \& K. C. PATHAK. 2004. Leaf and culm sheath morphology of some important bamboo species of Assam. J. Bamboo Rattan 3: 265-281. http://dx.doi.org/10.1163/1569159041765254

SODERSTROM, T. R. \& R. P. ELLIS. 1988. The woody bamboos (Poaceae: Bambuseae) of Sri Lanka: a morphological - anatomical study. Sm. C. Bot. 72: 1-75. http://dx.doi.org/10.5479/si.0081024x.72

SORENG, R. J., P. M.PETERSON, K. ROMASCHENKO, G. DAVIDS, F. O. ZULOAGA, E. J. JUDZIEWICZ, T. S. FILGUEIRAS, J. I. DAVIS \& O. MORRONE. 2015. A worldwide phylogenetic classification of the Poaceae (Gramineae). J. Syst. Evol. 53: 117-137. http://dx.doi.org/10.1111/jse. 12150

SORENG R. J., P. M. PETERSON, K. ROMASCHENKO, G. DAVIDSE, J. K. TEISHER, L. G. CLARK, P. BARBERÁ, L. J. GILLESPIE \& F. O. ZULOAGA. 2017. A worldwide phylogenetic classification of the Poaceae (Gramineae) II: An update and a comparison of two 2015 classifications. J. Syst. Evol. 55: 259-290. http://dx.doi.org/10.1111/jse.12262

TATEOKA, T., S. INOUE. \& S. KAWANO. 1959. Notes on some grasses IX: Systematic significance of bicellular microhairs of leaf epidermis. Bot. Gaz. 121: 80-91. http://dx.doi.org/10.1086/336048

VEGA, A. S.; M. A. CASTRO. \& C. GUERREIRO. 2016. Ontogeny of fusoid cells in Guadua species (Poaceae, Bambusoideae, Bambuseae): evidence for transdifferentiation and possible functions. Flora 222: 13-19.

http://dx.doi.org/10.1016/j.flora.2016.03.007

VIEIRA, R. C., D. M. S. GOMES, L. S. SARAHYBA \& R. C. O. ARRUDA. 2002. Leaf anatomy of three herbaceous bamboo species. Braz. J. Biol. 62: 907-922. http://dx.doi.org/10.1590/s1519-69842002000500021

WANG, R., N. XIA \& R. LIU. 2002. Micromorphological study on leaf epidermis of Bambusa and Dendrocalamus (Poaceae: Bambusoideae). J. Trop. Subtrop. Bot. 10: 22-26.

WANG, S., H. ZHANG, S. LIN, C. HSE \& Y. DIN. 2016. Anatomical characteristics of fusoid cells and vascular bundles in Fargesia yunnanensis leaves. J. For. Res. 27:1237-1247. http://dx.doi.org/10.1007/s11676-016-0271-9

WU, M. C. 1962. The classification of Bambuseae based on leaf anatomy. Bot. Bull. Acad. Sinica 3: 83-108.

YANG, H-Q., H. WANG \& D-Z. LI. 2008. Comparative morphology of the foliage leaf epidermis, with 


\section{F. Bessega et al. - Morfoanatomía de hojas de Bambusa}

emphasis on papillae characters, in key taxa of woody bamboos of the Asian tropics (Poaceae: Bambusoideae). Bot. J. Linn. Soc. 156: 411-423. http://dx.doi.org/10.1111/j.1095-8339.2007.00736.x

YORMANN, G. E. 2017. Anatomía caulinar y caracterización de las fibras de bambúes leñosos (Poaceae: Bambusoideae) nativos e introducidos de la Argentina para su aplicación a potenciales usos tecnológicos. Tesis Doctoral. Doctorado en Ciencias Aplicadas. Universidad Nacional de Luján. Buenos Aires, Argentina.

YORMANN, G. E., Z. E. RÚGOLO \& N. M. APÓSTOLO. 2020. Culms of Arundinaria simonii, Bambusa vulgaris cv. vittata and Phyllostachys aurea (Poaceae, Bambusoideae, Bambuseae): characterization of vascular bundles and fibers. Flora 263: 151523.

http://dx.doi.org/10.1016/j.flora.2019.151523

ZARLAVSKY, G. E. 2014. Histología Vegetal: técnicas simples y complejas. $1^{\circ}$ Edición. Sociedad Argentina de Botánica. Gráfica Arte, Buenos Aires.

ZHANG, Y. X., C. X. ZENG \& D. Z. LI. 2014. Scanning electron microscopy of the leaf epidermis in Arundinarieae (Poaceae: Bambusoideae): evolutionary implications of selected micromorphological features. Bot. J. Linn. Soc. 176: 46-65. http://dx.doi.org/10.1111/boj.12192 
